\title{
Study of Periostin, SerpinB2 and CLCA1Gene Expression as Potential Predictors of Corticosteroid Therapy Response in Childhood Asthma
}

I.A.M.Aly ${ }^{1}$, A.A.Sobeih ${ }^{1}$, R.F.Salem ${ }^{2}$ and D.A.Mohammed ${ }^{1}$

${ }^{1}$ Pediatrics Dept., Faculty of medicine, Benha Univ.,Benha, Egypt

${ }^{2}$ Biochemistry Dept., Faculty of medicine, Benha Univ.,Benha, Egypt

E-Mail:abdelr7mn35@gmail.com

\begin{abstract}
Currently, systemic corticosteroid treatment is considered themost effective medication for control of chronic asthma andrescue of acute exacerbation. Children can have poorly controlled asthma for numerous reasons. It is important to identify the underlying causes that contribute to poorly controlled asthma in each patient so that management strategies can be personalized to achieve the best outcomes. We have identified a biological basis for poor corticosteroid treatment response that can be used to distinguish a subgroup of children with asthma who respond poorly to treatment. nasal Periostin,SerpinB2 and CLCA1Gene expression might be a clinicallyuseful biomarker to identify a subset of children with difficult to-treat asthma with a biologic cause for poor corticosteroid response. Targeting Periostin,SerpinB2 and CLCA1 pathways in this subset might be a useful therapeutic strategy to enhance corticosteroid response.
\end{abstract}

\section{Introduction}

Prologue. Asthma influences 25. 7 million persons in the united States, including 7 million Youngsters [1]. In spite of the fact that asthmatic patients sharesimilar clinical symptoms, those infection may be heterogeneous [2]. this heterogeneity contributes of the challenge clinched alongside both considering andtreating asthma. Almost two thirds about asthmatic Youngsters reportedat minimum 1 assault in the previous year [3]. Highlighting those suboptimal administration of adolescence asthma [4]. The recurrence of absent orincomplete viability On asthma medication need been evaluated to make $40 \%$ should 70\%. [5] .Currently, systemic corticosteroid medicine will be acknowledged themost viable solution for control from claiming incessant asthma andrescue of intense worsening. Transcriptional profiling ofindividual group reactions is a fundamental and basic nextstep with exceptional comprehend this individual variety and identifybiomarkers from claiming systemic corticosteroid medicine reaction. Thisapproach need been utilized effectively on arrange sub phenotypes of asthma, including medication reaction phenotypes [6-9]. past investigations have regularly utilized specimens requiring bronchoscopy orinduced sputum collection, which is not constantly attainable inclinical practice, particularly Previously, know youngsters with a intense asthmaexacerbation (AAE). In the available examine we utilized genome-wideexpression profiling of nasal epithelial phones with distinguish geneswith transient outflow designs (before Also following treatment)that reliably What's more dependably discriminated the middle of systemic corticosteroid medication reaction gatherings Around kids hospitalized for asthma exacerbations. Nasal epithelial phones canbe promptly sampled securely Throughout a asthma attack [10] .What's more reflect transforms watched in the bronchial aviation routes for asthmatic know youngsters [11]. we distinguished Also replicated genes periostin,SerpinB2 Also CLCA1, the mrna statement for which consistentlydiscriminated the middle of great Also poor responders to systemic corticosteroid medicine.

\section{Methods \\ 2.1 Subjects}

Then afterward regulate Audit table approval, Youngsters provided for a analysis ofasthma In those period for 5 on 18 a considerable length of time who introduced of the Benha college healing facility crisis Branch (ED) for a AAE were recruited. Of the 40 subjects consented, 21 were hospitalized for asthma exacerbation, Also 15 required genome-wide mrna outflow information to both run through focuses. These 15 patients were utilized Similarly as a disclosure accomplice will test those affiliation the middle of gene interpretation and systemic corticosteroid medication reaction. An answer companion from claiming 25 know youngsters hospitalized to asthma were recruited to further accept the discoveries from those finding accomplice.

Subjects Gave demographic, environmental, asthma trigger, Furthermore personage Furthermore crew unfavorable susceptibility Also asthma history information. Parental report card about current breathed in corticosteroid (ICS) controller prescription (eg, mometasone, fluticasone, beclomethasonedipropionate,

fluticasone/salmeterol,mometasone/formoterolandbud esonide/formoterol might have been Additionally gathered. Will evaluate benchmark asthma manifestation seriousness Furthermore control, An respiratory side effect score might have been ascertained (based once recurrence of wheeze, cough, shortness of breath, and midsection tightness) [12] and the age-specific asthma control test score might have been gathered. [13].

\subsection{Treatment protocol and treatment response definitions}

Enrolled patients were treated according to the CCHMC evidence-basedtreatment protocol for inpatient asthma exacerbations [14-16]. The admitting physician determined the initial interval of albuterol treatments, which weresubsequently spaced based on physician or respiratory therapist assessments.Patients received $2 \mathrm{mg} / \mathrm{kg} / \mathrm{d}$ prednisone while hospitalized, and ICSs werecontinued through a mouthpiece. Length of stay (LOS) was calculated asthe number of hours from the 
time the admission decision was made to thetime the subject met clinical discharge criteria. Good responders were defined as thosewith an LOS of 24 hours or less, and poor responders were defined as thosewith an LOS of greater than 24 hours.

\subsection{Nasal epithelial cell sample collection and processing}

Nasal epithelial samples were collected at 2 time points from each subject (1) in the ED (S0) and (2) on the inpatient floor 18 to 24 hours after receiving corticosteroids in the ED (S1). Nasal samples collected contained more than 90\% epithelial cells.[10] Expression profiles were generated on the Affymetrix Human Gene 1.0 ST platform. Quantitative real-time PCR (qRT-PCR) was used to validate and replicate candidate genes.

\section{Statistical analysis}

3.1 Detection of differentially expressed genes in the discovery set

To identify candidate genes, we performed sequentialfiltering to balance concerns of type I and II errors. First, wesought to identify genes reliably expressed in nasal cells (raw signal $>100$ in at least 2 samples). Next, we sought to identify genes responsive to treatment (S1/S0 $>1.5$ or $\mathrm{S} 1 / \mathrm{S} 0<0.66$; $\mathrm{S} 1 / \mathrm{S} 0$ is defined as gene expression at $\mathrm{S} 1$ relative to that at $\mathrm{S} 0$ ). Then we identified genes with significant differences in S1/S0 ratio between the good and poor responder groups.

A P value threshold of .05 was used because independent replication samplesand complementary biologic studies minimize the risk of false-positive discovery to minimize the risk of missing true associations. We then identified those genes with a high rate of prediction accuracy $(>0.80)$ through lineardiscriminant analysis. To validate these results, we performed qRT-PCR.

\subsection{Microarray data analysis}

Microarray cell image files were analyzed with Gene Spring GX software. Probe-level measurements were subject to initial background correctionand normalization by using GC-robust multi-array average. Transcript levels were normalized per chip to the 50th percentile and per gene to median intensity.

\subsection{Association testing}

Table (1) Description of the discovery, and replication cohort
In the discovery phase we used t tests (withlog transformation) to identify genes between good and poor responders.

Linear discriminant analysis17was applied to find genes that bestdiscriminated between good and poor responders.For replication, we first examined whether there were differences betweenthe discovery and replication cohorts that might introduce bias. Time ofadmission was significantly different between the discovery and replicationcohorts. Thus we matched our replication cohort to the discovery cohort based on month and S0 and S1 times by using propensity scores [18]. Importantly, gene expression profiles were not considered in the matching process. Aftermatching, we performed $\mathrm{t}$ tests comparing the quantitative PCR results fromgood and poor responders. A linear regression model was fitted to examine the association between the Periostin,SerpinB2 and CLCA1mRNA expression change (S1/S0) andthe continuous length of hospital stay (in hours) in the combined discoveryand replication cohorts.

\section{Results \\ 4.1 Subjects}

The discovery and replication cohorts were primarily male Table (1). The discovery cohort was older than thereplication cohort, but within each cohort, there was no differencein age between the good and poor responders. There were nodifferences in individual parent-reported asthma triggers (datanot shown), mean baseline respiratory symptom frequencyscores, asthma control scores, or proportions of patientspresenting to the ED while receiving a controller medicine betweenthe discovery and replication cohorts Table (1). By design, the discovery and replication cohorts were similar with respect to month admitted, S0 time, and S1 time Table (1). Demographicsand clinical features were also compared between the good and poor responders, and no differences were detected Table (2).

The baseline average respiratory symptom score represents the average number of times per week the patient had coughing, wheezing, shortness of breath, or chest tightness, pain, or both. A score was assigned for each of the 4 symptoms, and then an average was taken. A higher score represents higher symptom frequency. The values of the scores for each symptom are as follows: 0 , never; 1 , less than 1 time per week; 2,1 to 2 times per week; 3,3 to 5 times per week; and 4,6 to 7 times per week.

\begin{tabular}{lccc}
\hline & Discovery cohort $(\mathbf{n = 1 5})$ & Replication cohort $(\mathbf{n ~ 5 = 2 5})$ & P value* \\
\hline Age $(\mathrm{y})$, mean $(\mathrm{SD})$ & $13.4(3.8)$ & $8.1(2.8)$ & $.0001_{-}$ \\
Age range (y) & $7.4-18.0$ & $5.0-15.1$ & $.73 \S$ \\
Male sex (\%) & 73.3 & 64.0 & - \\
Admission month, range & April-December & March-November & - \\
S0 sample time (24 h) & $9.3-20.8$ & $10.0-21.4$ & - \\
S1 sample time (24 h) & $8.1-16.7$ & $8.5-17.3$ & $.98 \_$ \\
ACT score (SD) & $16.0(2.5)$ & $16.0(4.4)$ & - \\
\hline
\end{tabular}


Table (1) Continue

\begin{tabular}{lccc}
\hline $\begin{array}{l}\text { Baseline average respiratory } \\
\text { symptom score (median) (SD) }\end{array}$ & $1.5(0.5)$ & $1.8(0.9) .18 \_1.8(0.8)$ & \\
$\begin{array}{l}\text { Presenting to ED on ICS controller } \\
\text { medicine }(\%)\end{array}$ & 26.7 & 32.0 & $1.00 \S$ \\
\hline
\end{tabular}

ACT, Asthma Control Test.

*Comparison between discovery and replication cohort populations. -Student t test. -Mann-Whitney U test. -Fisher exact test.

Table (2) Demographics and clinical features of good and poor responders

\begin{tabular}{|c|c|c|c|}
\hline \multicolumn{4}{|l|}{ Good responders $(n=21)$ Poor responders $(n=19) P$ value* } \\
\hline $\operatorname{Age}(y)$, mean $(S D)$ & $0.2(4.2)$ & $9.9(4.2)$ & .79 \\
\hline Male sex $(\%)$ & 70.0 & 69.7 & .98 \\
\hline Admission month range & a-December & \multicolumn{2}{|c|}{ February-November - } \\
\hline So sample time (24 h) & $0.0-20.5$ & 9.3-21.4 & - \\
\hline S1 sample time ( $24 \mathrm{~h})$ & $8-14.8$ & 7.7-17.6 & - \\
\hline ACT score (SD) & (4.0) & $16.2(3.3)$ & .95 \\
\hline Baseline average respiratory symptom score, median (SD) & $1.7(0.8)$ & $1.7(0.7)$ & $.55_{-}^{-}$ \\
\hline Presenting to ED on ICS controller medicine (\%) & 35.0 & 36.4 & .92 \\
\hline
\end{tabular}

For a definition of the baseline average respiratory symptom score, see the footnote for Table (1). *Comparison between good and poor responders.

_x2 Test.

4.2 Identificationof genes differentially expressed between good and poor responder groups in the discovery cohort

We used a multistep filtering process to identify genes. Starting with more than 20,000 genes, we identified 8 genes that were nominally significant $(\mathrm{P}<$ $.05)$ and had a prediction accuracy of 0.80 or greater. Of these 8 genes, qRT-PCR expression of superoxide dismutase 2 (SOD2), tyrosine protein kinase(HCK),serglycin(SRGN), Periostin,SerpinB2 and CLCA1 was significantly induced at $\mathrm{S} 1$ in the good compared with the poor responder groups. CD300A was not detectable in most samples, and reliable results could not be achieved for lymphocyte cytosolic protein 2 (LCP2), formyl peptide receptor 1 (FPR1), and lowaffinity immunoglobulin $\mathrm{g} F \mathrm{Fc}$ region receptor IIIA(FCGR3A) because of low copy numbers.

4.3 Periostin,SerpinB2 and CLCA1 mRNA expression change predicts corticosteroid treatment response in the replication cohort

To substantiate our findings, we recruited an independentprospective cohort to serve as a replication. High baseline mRNAexpression of Periostin,SerpinB2 and CLCA1 occur in the good responder group comparedwith that seen in the poor responder group,replicating our findings from the discovery cohort. Expression of SOD2, HCK, and SRGN was not significantly different between the treatment response groups(data not shown).

To evaluate whether the observed Periostin, SerpinB2 and CLCA1 mRNA expressionchange was attributable to a baseline difference in Periostin,SerpinB2 and CLCA1
_Mann-Whitney U test.

mRNA expression at s0, we compared Periostin,SerpinB2 and CLCA1 expression at S0of all patients; no significant difference was detected. To test whether the baseline ICS exposure was aconfounding factor for the corticosteroid treatment response,we compared the proportion of subjects who presented to theED while receiving ICSs between the good and poor responders; no significant difference was detected Table (2).

\section{Discussion}

Following regulate survey table approval, Youngsters provided for a analysis ofasthma toward those agdistis from claiming 5 should 18 quite some time who introduced of the Benha school clinic crisis section (ED) with an AAE were recruited. Of the 40 subjects consented, 21 were hospitalized to asthma exacerbation, Furthermore 15 required genome-wide mrna statement information to both occasion when focuses. These 15 patients were utilized Concerning illustration An disclosure companion to test those companionship between gene interpretation Also systemic corticosteroid medication reaction. A answer associate from claiming 25 know youngsters hospitalized for asthma were recruited should further accept those discoveries starting with the finding associate.

Subjects Gave demographic, environmental, asthma trigger, Also individual Furthermore crew unfavorable susceptibility Also asthma history information. Parental report card of present breathed in corticosteroid (ICS) controller solution (eg, mometasone, fluticasone, beclomethasonedipropionate,

fluticasone/salmeterol,mometasone/formoterolandbudeso 
nide/formoterol might have been also gathered. On assess benchmark asthma manifestation seriousness Also control, a respiratory manifestation score might have been ascertained (based ahead recurrence of wheeze, cough, shortness about breath, and midsection tightness),[12] and the age-specific asthma control test score might have been gathered. [13].

\section{Referances}

[1] L.J. Akinbami, J.E. Moorma, C.Bailey, Trends in asthma prevalence, health care use, and mortality in the United States. NCHS Data Brief., Vol.94,PP.18,2010 .

[2] E.H.Bel,Mildasthma.NEnglJ.Med.,vol369.PP.2362,2 013

[3] B.Fassl, F.Nkoy, B.Stone, R.Srivastava, The Joint Commission Children's Asthma Care quality measures and asthma readmissions. Pediatrics.,Vol.130.PP.482-91,2012.

[4] L.Akinbami, Centers for Disease Control and Prevention National Center for Health Statistics. The state of childhood asthma, UnitedStates,AdvData., Vol.381,PP.1-24,2006.

[5] J.M. Drazen, E.K. Silverman,T.H. Lee.

[6] Heterogeneity of therapeutic responses in asthma. Br Med Bull.,Vol.56,PP.1054-70,2000.

[7] P.G.Woodruff,H.A.Boushey,G.M.Dolganov, Genome-wide profiling identifies epithelial cell genes associated with asthma and with treatment response to corticosteroids .Proc Natl Acad Sci U S A.,Vol.104,PP.15858-63,2007.

[8] P.G.Woodruff,B.Modrek,D.F.Choy,G.Jia,T-helper type 2-driven inflammation defines major subphenotypes of asthma. Am J RespirCrit Care Med.,Vol.180,PP.388-95,2009.

[9] Y.Huang, A.K.Zaas, A.Rao, N.Dobigeon, Temporal dynamics of host molecular responses differentiate symptomatic and asymptomatic influenza A infection. PLoS Genet .,Vol.7,2011.

[10] K.J.Baines, Baines J.LBaines., L.GWood, R.J.Scott, Sputum gene expression signature of 6 biomarkers discriminates asthma inflammatoryphenotypes.JAllergyClinImmunol.Vol., 133,PP.997-1007,2014.

[11] J.R.Guajardo, K.W.Schleifer, M.O.Daines, Altered gene expression profiles in nasal respiratory epithelium reflect stable versus acute childhood asthma. J Allergy ClinImmunol.Vol.115,PP.24351,2005 .

[12] A. Poole, C. Urbanek, C. Eng, Dissecting childhood asthma with nasal transcriptomics distinguishes subphenotypes of disease. J AllergyClinImmunol.,Vol.133,PP.670-8,2014.

[13] M. Butsch Kovacic, J.M. Biagini Myers, M.Lindsey, The Greater Cincinnati Pediatric Clinic Repository: a novel framework for childhood asthmaandallergyresearch.PediatrAllergyImmunolPul monol.Vol.25,PP.104-13,2012.

[14] A. H. Liu, R. S. Zeiger, C .A. Sorkness, N.K.Ostom, The Childhood Asthma Control Test: retrospective determination and clinical validation of a cut point to identify children withverypoorlycontrolledasthma.,Vol.126,2010.

[15] J. Allergy Clin Immunol, Evidence-based care guideline for management of acute exacerbation of asthma in children aged 0 to 18 years. Rockville (MD): Agency for Healthcare Research and Quality (AHRQ). Availableat: http:// www. guideline. gov/content. aspx?id524528. Accessed September 16, 2010.

[16] S.E. Muething, Improving patient outcomes bystandardizingcare.JPediatr.,Vol.147,pp56870,2005 .

[17] W.E. Gerhardt, Schoettker PJ, Donovan EF, Putting evidence-based clinical practice guidelines into practice: an academic pediatric center's experience. JtComm J Qual Patient Saf .,Vol.33,pp226-35,2007.

[18] B.D. Ripley, Pattern recognition and neural networks. Cambridge (United Kingdom), The Press Syndicate of the University of Cambridge.,Vol.45,.1996.

[19] P.C. Austin, An introduction to propensity score methods for reducing theeffects of confounding in observational studies. Multivariate Behav Res .,Vol.46,PP.399-424,2011.

[20] J. Bousquet, E. Mantzouranis, A.A. Cruz, Uniform definition of asthma severity, control, and exacerbations: document presented for the World Health Organization Consultation on Severe Asthma. J Allergy ClinImmunol .,Vol.126,PP.926-38,2010.

[21] M.C. Bell, W.W. Busse, Severe asthma: an expanding and mounting clinical challenge. J Allergy ClinImmunol Pract.Vol.1,pp110-22,2013.

[22] D.Desai, C.Brightling, Cytokine and anti-cytokine therapy in asthma: ready for the clinic?Clin Exp Immunol., Vol.158,PP.10,2009.

[23] J.Corren, R.F.Lemanske, N.A.Hanania, Lebrikizumab treatment in adults with asthma. N Engl J Med .Vol.365,PP.1088-98,2011.

[24] S. Wenzel, L.Ford, D.Pearlman, S.Spector, Dupilumabin persistent asthma with elevated eosinophil levels. N Engl J Med .,Vol.368,PP.245566.2013.

[25] L.Gillan, D. Matei, D.A. ,Fishman , Cancer Res.,Vol.62,pp5358-5364,2002.

[26] S.Bao,G.Ouyang ,X.Bai ,Z.Huang ,Cancer Cell.,Vol.5,PP.329-339,2004.

[27] R.Shao, S.Bao, X.Bai, C.Blanchette ,Mol Cell Biol.Vol.24,PP.3992-4003,2004

[28] R.A. Norris ,B.Damon ,V.Mironov, J.Cell Biochem.,Vol. 101,PP.695-711,2007.

[29] G.Takayama,K.Arima,T.Kanaji ,S.Toda,JAllerg yClinImmunol.Vol. 118,PP.98-104,2006.

[30] R.L. edcalf, S.J. Stasinopoulos, FEBS J.,Vol. 272,PP.4858-4867,2006.

[31] S.S. Wagers , L.M .Rinaldi ,J.H. Bates ,J Clin Invest.Vol.114,PP.104-111,2004.

[32] A. Nakanishi, S. Morita, H. Iwashita et al. Role of gob-5 in mucus overproduction and airway hyper 
responsiveness in asthma. Proc Natl Acad Sci USA .,Vol.98,PP.5175-5180,2001.

[33] A.D. Gruber.,R.C. Elble.,H.LJi, Genomic cloning, molecular characterization, and functional analysis of human CLCA1, the first human member of the family of $\mathrm{Ca}^{2+}$ activated $\mathrm{Cl}^{-}$channelproteins. Genomics., Vol. 54,PP. 200-214,1998

[34] M. Agnel., T.V. ermat, J.M. Culouscou, Identification of three novel members of the calciumdependent chloride channel (CaCC) family predominantly expressed in the digestive tract and trachea. FEBS.Vol.455,„PP.295-301, 1999.
[35] H.P. Hauber, J.J. Manoukian, L.H. Nguyen, Increase dexpression of interleukin-9, interleukin-9 receptor, and the calcium-activated chloride channel hCLCA1 in the upper airways ofpatientswithcysticfibrosis.Laryngoscope.,Vol.113,PP. 1037-1042, 2003.

[36] M.Hoshino, S. Morita,H. Iwashita, Increased expression of the human $\mathrm{Ca}^{2+}$-activated $\mathrm{Cl}^{-}$channel 1 (CaCC1) gene in the asthmatic airway.Am.J.RespirCritCareMed.,Vol.165,PP. 1132$1136,2002$. 